\title{
Antifungal activity of aqueous and corn steep liquor extract of Ficus exasperata, Anonna muricata and Azadiractha indica
}

\author{
Temilola Akinkugbe ${ }^{1}$, Samuel Bankole ${ }^{2}$, Paul Ogunbamowo $^{2, *}$, and Olamilekan \\ AWOTEDU ${ }^{2}$ \\ ${ }^{1}$ Federal University of Agriculture, Abeokuta, College of Bioscience, PMB 2240, Alabata Road, Abeokuta, Ogun State, Nigeria \\ ${ }^{2}$ Forestry Research Institute of Nigeria, Ibadan, Biomedicinal Research Centre, PMB 5054, Jericho Hills Ibadan, Nigeria \\ *Corresponding author: olutimmy7@gmail.com
}

Received: April 3, 2020

Accepted: May 19, 2020

Published on-line: September 14, 2020

Published: December 25, 2020

\begin{abstract}
This study investigated the activity of aqueous and corn steep liquor (CSL) extracts of Ficus exaperasta, Annona muricata and Azadirachta indica against Candida spp. isolated from high vaginal swab samples. Phytochemical screening of the plants was done using standard methods, the antifungal activity of the plant's extracts and standard drugs were tested against isolates of Candida spp. using the agar well diffusion method; the minimum inhibitory concentration (MIC) and minimum fungicidal concentration (MFC) were also determined using microdilution standardized techniques. Phytochemical screening of the aqueous and CSL extracts of the plants revealed the presence of tannin, saponin, flavonoids, and terpenoids. Among the five Candida strain isolates, the zone of inhibition produced by the plant extracts against $C$. albicans shows a range of $0-18.3 \mathrm{~mm}$; . krusei (strain A): $5.1-24.5 \mathrm{~mm}$; . krusei (strain B): 0-18.0 mm; C. kefyr (strain A): 6.1-27.5 mm; and C. kefyr (strain B): 0-22.0 mm. The CSL extract had higher inhibitory action compared with aqueous extract, also $F$. exasperata and A. muricata gave better antifungal activity against the tested Candida strains. The MIC of the aqueous and CSL extracts of the F. exasperata ranged between $6.25-12.50 \mathrm{mg} / \mathrm{mL} ; A$. muricata: $3.125-12.500 \mathrm{mg} / \mathrm{mL}$, while the aqueous and CSL extracts of $A$. indica was found to have no activity at all the tested concentrations against $C$. albicans, $C$. krusei (strain A) and C. krusei (strain B), similar observation for the MFC. This study proved the antifungal efficacy of aqueous and CSL extracts of $F$. exasperata, A. muricata, and $A$. indica against isolates of Candida species which are usually implicated in candidiasis.
\end{abstract}

Key words: Candida species; Ficus exasperata; Annona muricata; Azadirachta indica; Corn Steep Liquor; Antifungal activity http://dx.doi.org/10.5937/leksir2040005A

\section{INTRODUCTION}

Fungal infections continue to be a source of concern for public health as it is known to affect many people worldwide. In recent times, infections caused by fungi are considered to be the fourth foremost causes of infections spread by blood where the prominent fungi concerned are those of Candida species (Pierce, 2005; Tsai et al., 2013). Candida spp. is one of the common fungal infection plaguing humans. These yeast species are characterized by a thin cell wall, ovoid cells that are typically 3-5 $\mu \mathrm{m}$ in diameter, often forming the normal flora of skin, mouth, vagina, and intestine. They are also known to be opportunistic pathogens that infect people with low immunity (Calderone and Fonzi, 2001; Rahman et al., 2011). Candida remains the major fungal pathogen responsible for the majority of human infections ranging from localized superficial to systemic candidiasis. It accounts for over $50 \%$ of all cases in the world, while an increase in the prevalence of yeast infections caused by Candida species other than C. albicans such as C. glabrata, C. krusei, C. tropicalis, and C. parapsilosis has been reported in different parts of the world (Pfaller and Diekema, 2007; Pinto et al., 2009). Thus, the quality of life could be affected by a fungal infection which is usually treated using antifungal medications. Some of these medications apart from being costly, have unpleasant side effects and may cause the resistance of the organisms to the antifungal agent. Consequently, there is a constant search for alternative antifungal treatments some of which are obtained from medicinal plants.

Medicinal plants form the backbone of traditional/alternative system of medicine and they have been the subject of research interest for pharmacological studies in the last couple of decades. This is as a result of the acceptance of the value of 
medicinal plants as a possible source of novel compounds of therapeutic importance (Prusti et al., 2008). Among plants of medicinal importance, Ficus exasperata, Annona muricata, and Azadirachta indica are used for various therapeutic purposes.

Ficus exasperata Vahl. belongs to the family Moraceae and it is locally known as "sandpaper tree" and "Ewe ipin" in the Yoruba language of Western Nigeria. Different parts of the plant are locally used for treating various infectious diseases such as eye-sores, ringworm, stomach pains and leprosy, etc. (Bafor and Igbinuwen, 2009). Some pharmacological activities like anti-hypertensive, antioxidant, anti-inflammatory, antiulcer, anti-lipidic, anti-bacterial, and anti-fungal have been documented for F. exasperata (Sonibare et al., 2006).

Annona muricata L. belongs to the family Annonaceae, it is locally called soursop due to the slightly acidic taste of the fruit when ripe (Hutchinson and Dalziel, 2000). Different parts of the plants have been previously reported to possess bioactivity. For instance, its leaves and stem are considered to show cytotoxicity against cancer cells as a result of a compound called acetogenin activity which is not toxic to normal cells (Oberlies et al., 1995). Acetogenins and other phytocompounds present in the plant have collectively exhibited antitumor, parasiticidal, pesticidal, and antimicrobial activities (McLaughlin, 2008).

Azadirachta indica A. Juss. commonly-known as neem belongs to the family Meliaceae. It is indigenous to India and established in many of the tropical and subtropical countries including Nigeria. The plant has been reported to possess many pharmacological activities such as antioxidant and antifungal among others (Choudhary et al., 2017; Itelima et al., 2016; Mondall et al., 2009; Nahak and Sahu, 2010).

The bioactive substances in these plants are usually extracted with a wide range of solvents for various ethnobotanical applications. The literature is also well supported with information on the antimicrobial properties of various extracts of $F$. exasperata (Adebayo et al., 2009; Ajayi et al., 2012; Takon, 2013), A. muricata (Vijayameena et al., 2013) and A. indica (Mohammed and Omer, 2017). However, none of these studies has reported the activity of corn steep liquor (CSL) extracts against fungal species. The CSL which is a by-product of the wet corn milling process (Abdus-Salaam et al., 2014), and water are commonly used to prepare herbal decoctions which are utilized in the treatment and management of various disorders including fungal infection. In this study, we present findings on the antifungal activity of aqueous and corn steep extracts of $F$. exasperata, $A$. muricata, and $A$. indica against vaginal isolates of Candida species.

\section{MATERIALS AND METHODS}

\subsection{Plant materials and extraction procedures}

Leaves samples from F. exasperata, A. muricata and A. indica were collected in the early hours of the day from the arboretum of the Department of Forestry and Wildlife Management, Federal University of Agriculture, Abeokuta, Nigeria. The plant specimens were identified at the Forest Herbarium Ibadan. The leaves samples were air-dried for two weeks on a cabinet dryer and then milled to powdered form. Freshly made corn steep liquor (CSL), a byproduct of the corn wet milling process, was obtained from the local makers of pap, the main product of the wet milling process. Aqueous and CSL extracts were of the three plants were prepared according to the method previously used by Pai et al. (2010) with modifications. Sterile distilled water and CSL (both $500 \mathrm{~mL}$ ) were used to extract 50 $\mathrm{g}$ of the powdered plant samples by boiling for 30 minutes on a hot plate $\left(100{ }^{\circ} \mathrm{C}\right)$, allowed to cool and filtered using a sterile filter paper. The concentration of the filtrates was reduced to a semi-solid mass on a water bath to get the crude extracts of the three plant samples which were then stored at $4{ }^{\circ} \mathrm{C}$ in preparation for the phytochemical screening and fungal susceptibility testing of the extracts described in the subsequent sections.

\subsection{Collection and isolation of Candida strains}

High vaginal swabs from suspected cases of Candida infection were obtained from the Federal Medical Centre, Abeokuta. The obtained swabs containing Candida spp. were cultivated on potato dextrose agar (PDA) and Candida strains identified using standard microbiological procedures (Shah et al., 2012; Galle and Gianinni, 2004). In brief, macroscopic examination of the cultures considered rate of growth, colonial morphology, pigment production, texture, and colour of surface or reverse, while microscopic examination was done using the germ tube test.

\subsection{Phytochemical analysis}

Phytochemical screening of the plant extracts was carried out using standard methods for determination of tannins, saponins, anthraquinones, flavonoids, and terpenoids' presence. In brief, $2 \mathrm{~g}$ of the crude extract was re-dissolved in 10 $\mathrm{mL}$ of distilled water and CSL, then the presence of tannin was detected using the ferric chloride test, saponin's presence was detected using the Frothing test, anthraquinone was determined using the Bontrager's test, flavonoid was detected using the lead acetate test, while terpenoids' screening was done using the Salkowski's test (Harborne, 1973; Obasi et al., 2010; Roopashree et al., 2008).

\subsection{Sensitivity testing of aqueous and corn steep liquor plant extracts against Candida isolates}

Agar well diffusion method was used to test the sensitivity of the Candida isolates to the aqueous and CSL leaves extracts. This was done according to the method described by Kareem et al. (2010). Sterile cotton-wool swab was dipped into prepared inoculum and spread all over PDA plate. After each swabbing, the swab was passed around the edges of the agar surface medium and left to dry for few minutes at room temperature with the lid closed. Then, by using a sterile cork borer, four wells of $4 \mathrm{~mm}$ in diameter representing the four concentrations $(100,75,50$ and $25 \mathrm{mg} / \mathrm{mL})$ of the sample extracts were made in the inoculated plate and each well labeled for each concentration. The three plants' crude extracts were each reconstituted with sterile distilled water and CSL to a stock concentration of $200 \mathrm{mg} / \mathrm{mL}$ after which four working concentrations of $100,75,50$ and $25 \mathrm{mg} / \mathrm{mL}$ of aqueous and CSL of extracts of each plant were prepared from the stock then, 50 $\mu \mathrm{L}$ of each concentration was introduced into the respective wells using a micropipette in the inoculated plates. The plates were left for half an hour with the lid closed. The plates were incubated at $28{ }^{\circ} \mathrm{C}$ for $24 \mathrm{~h}$ and then observed for the zone of inhibition which is characterized by the clear area around the well. The experiment was done in triplicates and the zone of growth inhibition was measured with a transparent ruler and expressed in millimeters.

\subsection{Determination of the minimum inhibitory concentration of plant extracts on Candida isolates}

The modified method of Malwal and Sarin (2011) was employed for the determination of the minimum inhibitory concentration (MIC) of extract using the broth dilution method. For the broth dilution, the growth concentration was adjusted to $10^{5}$ organisms / mL by using $0.5 \mathrm{~mL}$ McFarland turbidity 
Table 1. Results of phytochemical screening of aqueous and CSL extracts of the test plants

\begin{tabular}{|c|c|c|c|c|c|c|}
\hline \multirow[b]{2}{*}{ Phytochemical } & \multicolumn{2}{|c|}{ F. exasperata } & \multicolumn{2}{|c|}{ A. muricata } & \multicolumn{2}{|c|}{ A. indica } \\
\hline & Aqueous & CSL & Aqueous & CSL & Aqueous & CSL \\
\hline Tannin & + & + & + & + & + & + \\
\hline Saponin & + & + & + & + & + & + \\
\hline Anthraquinone & - & - & - & - & - & - \\
\hline Flavonoids & + & + & + & + & + & + \\
\hline Terpenoids & + & + & + & + & + & + \\
\hline
\end{tabular}

standard. Aqueous and CSL solution of $25 \%$ was prepared from the leaves extracts as the stock solution. Potato dextrose broth $(5 \mathrm{~mL})$ was added in MIC tubes. One milliliter of plant extracts stock was added to each tube containing the broth at various concentrations $(25,12.5,6.25$ and $3.125 \%)$. The tubes were incubated at $28^{\circ} \mathrm{C}$ for 48 hours and observed for visible growth after shaking the tubes gently to mix. The experiment was done in duplicate. The MIC was taken as the lowest concentration of the extracts at which there is no turbidity after incubation. The negative control containing only broth appeared clear.

\subsection{Determination of the minimum fungicidal concentration (MFC) of plant extracts on Candida isolates}

This is usually carried out after MIC test, to determine the minimum concentration of the test antifungal agent that will kill the microorganism. The contents of the MIC wells were inoculated on sterile PDA separately. The plates were labeled indicating the well from which the isolate was plated and incubated at $28^{\circ} \mathrm{C}$ for 48 hours for growth. Plates that showed growth of organisms were checked to determine the wells from which they were inoculated. The lowest concentration of the wells from which the plates were inoculated that did not show any growth was considered as the MFC of the organism (Levinson, 2016).

\subsection{Antifungal susceptibility pattern}

Antibiogram was performed using the method of Clinical and Laboratory Standards Institute (Kanthasamy et al., 1989). An inoculum was prepared and its turbidity was adjusted visually with the transmittance to that produced by a $0.5 \mathrm{McF}$ arland standard. After obtaining the $0.5 \mathrm{McF}$ arland standards for isolated species of Candida they were swabbed uniformly on the surface of Muller Hinton agar and allowed to dry under sterile conditions. After drying, antifungal discs of three commercial antibiotics namely Amphotericin B, Fluconazole and Ketoconazole were placed onto the surface of inoculated plates of Candida. The plates were incubated at $35^{\circ} \mathrm{C}$ for 24 hours and after incubation zones of growth inhibition were measured, results were recorded as susceptible or resistant.

\section{RESULTS}

In other to assess the antifungal effects of CSL and aqueous extracts of three medicinal plants on clinical isolates of Candida spp., high vaginal swab samples obtained from suspected cases of candidiasis were used to isolate and test the potential effect of the tested extracts against the isolated organisms adopting the agar well diffusion method. Results from the high vaginal swab samples revealed that three Candida species were identified. One strain of $C$. albicans has been identified, while C. kefyr and C. krusei had two strains each. The morphological analysis of the three species showed that isolates had cream colour, spherical shape and the surface margin entire.
C. albicans had a flat elevation while the strains of C. kefyr and C. krusei had a raised elevation. The biochemical analysis showed that the three species were urea negative. C. kefyr and C. krusei were also germ tube negative, while C. albicans was germ tube positive. The results of the phytochemical screening of the aqueous and CSL extracts of the species F. exasperata, A. muricata and $A$. indica are presented in Table 1 . The results show the presence of all observed phytochemical compounds except anthraquinone.

The inhibitory activity of the aqueous and CSL extracts of tested medicinal plants against the isolated strains of Candida spp. is represented in Table 2. The mean zone of inhibition produced by the plant extracts against $C$. albicans show that for F. exasperata it ranged from $0-16.8 \mathrm{~mm}$, for $A$. muricata ranged from 9.1-18.3 mm while for $A$. indica it ranged from 0-10.4 mm; the mean zone of inhibition observed in C. krusei (Strain A) indicate that for F. exasperata it ranged from 9.8-24.5 mm, for A. muricata it ranged from $9.4-23.4 \mathrm{~mm}$ while for $A$. indica it ranged from 5.3-14.4 $\mathrm{mm}$; the mean zones of inhibition produced against $C$. krusei (Strain B) revealed that for F. exasperata it ranged from $0-18.0 \mathrm{~mm}$, for A. muricata it ranged from 8.2$17.5 \mathrm{~mm}$ compared while for A. indica it ranged from $0-11.8$ $\mathrm{mm}$. Also, the mean inhibition zones produced against $C$. kefyr (Strain A) revealed that for F. exasperata it ranged from 10.3$25.1 \mathrm{~mm}$, for $A$. muricata it ranged from $18.4-27.5 \mathrm{~mm}$ while for $A$. indica it ranged from $6.1-16.3 \mathrm{~mm}$; against against $C$. kefyr (Strain B), the mean zones of inhibition revealed that for $F$. exasperata it ranged from 0-19.1 mm, for $A$. muricata it ranged from 2.1-22.0 mm while for $A$. indica it ranged from 0-16.4 $\mathrm{mm}$. Both aqueous and CSL extracts of $A$. muricata had higher inhibitory activity compared with the other plants against all the Candida spp. while the least inhibitory effect was observed in $A$. indica.

The results of the antifungal sensitivity testing of the Candida strains against three commercial antibiotics are also shown in Table 2. Amphotericin B had the most sticking antifungal effect against the five strains of Candida spp. with the growth inhibition zone ranging from $15.0-21.0 \mathrm{~mm}$ while fluconazole had inhibitions on only the two strains of C. kefyr, while all the Candida strains demonstrated significant susceptibility to Ketonidazole except $C$. albicans. The result also suggests that the CSL extracts of $A$. muricata at the concentration range of $50-100 \mathrm{mg} / \mathrm{mL}$ showed better antifungal activity against the $C$. kefyr (Strain A) when compared with the standard antifungal drugs.

The results of the Minimum Inhibitory Concentrations (MICs) and Minimum Fungicidal Concentration (MFC) of the plant extracts against the tested Candida strains are presented in Table 3. The MICs of the aqueous and CSL extracts of the three medicinal plants were obtained by the broth dilution method where the MICs were determined as the lowest concentration of aqueous and CSL extracts that gave sterile culture after incubation. The MIC of the aqueous and CSL extracts of the 
Table 2. Mean inhibition zone ( $\mathrm{mm})$ of Candida species after application of aqueous and CSL extracts of $F$. exaperasta, $A$. muricata, and $A$. indica with commercial antibiotics as a control

\begin{tabular}{|c|c|c|c|c|c|c|c|}
\hline \multirow[b]{2}{*}{ Species } & \multirow[t]{2}{*}{ Extract } & \multirow{2}{*}{$\begin{array}{r}\text { Conc. } \\
{[\mathrm{mg} / \mathrm{mL}]}\end{array}$} & \multirow[t]{2}{*}{ C. albicans } & \multicolumn{2}{|c|}{ C. krusei } & \multicolumn{2}{|c|}{ C. kefyr } \\
\hline & & & & Strain A & Strain B & Strain A & Strain B \\
\hline \multirow[t]{8}{*}{ F. exasperata } & Aqueous & 25 & - & $9.8 . \pm 0.9$ & $6.2 \pm 0.6$ & $17.2 \pm 1.7$ & - \\
\hline & CSL & 25 & $6.0 \pm 0.2$ & $14.1 \pm 0.8$ & - & $10.3 \pm 0.6$ & $14.1 \pm 1.4$ \\
\hline & Aqueous & 50 & $3.3 \pm 0.6$ & $11.7 \pm 1.4$ & $9.2 \pm 1.3$ & $19.4 \pm 1.2$ & $10.0 \pm 1.0$ \\
\hline & CSL & 50 & $10.6 \pm 1.3$ & $18.2 \pm 1.9$ & $12.5 \pm 1.0$ & $13.1 \pm 0.5$ & $17.2 \pm 2.1$ \\
\hline & Aqueous & 75 & $10.3 \pm 0.8$ & $16.3 \pm 1.2$ & $11.9 \pm 0.8$ & $24.3 \pm 2.0$ & $14.4 \pm 1.4$ \\
\hline & CSL & 75 & $14.2 \pm 1.7$ & $20.6 \pm 1.3$ & $18.0 \pm 1.4$ & $18.3 \pm 0.8$ & $19.1 \pm 1.3$ \\
\hline & Aqueous & 100 & $13.1 \pm 0.9$ & $21.3 \pm 1.7$ & $15.1 \pm 1.2$ & $25.1 \pm 1.9$ & $15.7 \pm 0.8$ \\
\hline & CSL & 100 & $16.8 \pm 1.4$ & $24.5 \pm 2.3$ & $11.8 \pm 1.3$ & $23.0 \pm 1.6$ & $17.6 \pm 1.5$ \\
\hline \multirow[t]{8}{*}{ A. muricata } & Aqueous & 25 & $9.1 \pm 1.1$ & $12.1 \pm 0.8$ & $8.2 \pm 0.7$ & $19.2 \pm 2.2$ & $2.1 \pm 0.5$ \\
\hline & CSL & 25 & $11.5 \pm 0.6$ & $9.4 \pm 0.8$ & $12.2 \pm 0.7$ & $18.4 \pm 1.4$ & $11.4 \pm 1.1$ \\
\hline & Aqueous & 50 & $12.4 \pm 1.2$ & $16.2 \pm 1.2$ & $8.2 \pm 1.4$ & $22.0 \pm 1.7$ & $5.0 \pm 0.5$ \\
\hline & CSL & 50 & $14.1 \pm 0.5$ & $17.3 \pm 1.2$ & $13.5 \pm 1.5$ & $23.4 \pm 2.1$ & $18.0 \pm 1.2$ \\
\hline & Aqueous & 75 & $15.3 \pm 0.9$ & $22.2 \pm 1.7$ & $14.1 \pm 1.2$ & $23.8 \pm 1.4$ & $12.1 \pm 1.8$ \\
\hline & CSL & 75 & $16.2 \pm 1.4$ & $18.1 \pm 0.8$ & $14.3 \pm 0.7$ & $24.1 \pm 1.6$ & $17.2 \pm 1.6$ \\
\hline & Aqueous & 100 & $17.7 \pm 1.5$ & $22.7 \pm 1.6$ & $17.0 \pm 0.8$ & $25.5 \pm 1.8$ & $14.3 \pm 1.2$ \\
\hline & CSL & 100 & $18.3 \pm 1.8$ & $23.4 \pm 1.8$ & $17.5 \pm 1.2$ & $27.5 \pm 0.6$ & $22.0 \pm 1.7$ \\
\hline \multirow[t]{8}{*}{ A. indica } & Aqueous & 25 & - & $5.3 \pm 0.6$ & - & $6.1 \pm 0.4$ & - \\
\hline & CSL & 25 & - & $5.9 \pm 0.3$ & $2.0 \pm 0.6$ & $7.2 \pm 0.8$ & - \\
\hline & Aqueous & 50 & - & $10.0 \pm 1.5$ & - & $10.3 \pm 1.6$ & $4.2 \pm 0.4$ \\
\hline & CSL & 50 & - & $6.8 \pm 0.4$ & $6.4 \pm 1.4$ & $9.1 \pm 0.4$ & $8.1 \pm 0.8$ \\
\hline & Aqueous & 75 & - & $11.2 \pm 0.8$ & $4.2 \pm 0.8$ & $11.7 \pm 0.8$ & $7.8 \pm 1.2$ \\
\hline & CSL & 75 & $7.5 \pm 0.7$ & $11.8 \pm 1.3$ & $11.4 \pm 1.4$ & $11.4 \pm 1.1$ & $10.3 \pm 1.4$ \\
\hline & Aqueous & 100 & - & $13.3 \pm 1.2$ & $9.0 \pm 0.9$ & $14.2 \pm 1.2$ & $12.2 \pm 0.9$ \\
\hline & CSL & 100 & $10.4 \pm 1.6$ & $14.4 \pm 0.7$ & $11.8 \pm 1.6$ & $16.3 \pm 0.8$ & $16.4 \pm 1.3$ \\
\hline Antibiotics & & {$[\mu \mathrm{g} / \mathrm{mL}]$} & & & & & \\
\hline Fluconazole & & 10 & - & - & - & $20.3 \pm 0.7$ & $15.2 \pm 1.1$ \\
\hline Ketonidazole & & 10 & - & $17.2 \pm 0.1$ & $19.1 \pm 0.2$ & $22.0 \pm 1.5$ & $18.2 \pm 0.8$ \\
\hline Amphotericin B & & 10 & $21.0 \pm 0.2$ & $20.3 \pm 0.1$ & $15.0 \pm 0.5$ & $19.4 \pm 1.8$ & $18.1 \pm 1.2$ \\
\hline
\end{tabular}

Table 3. Minimum inhibitory concentration (MIC) $(\mathrm{mg} / \mathrm{mL}$ ) and minimum fungicidal concentrations (MFC) $(\mathrm{mg} / \mathrm{mL})$ of aqueous and CSL extracts of test plants against isolates of Candida species

\begin{tabular}{|c|c|c|c|c|c|c|c|c|}
\hline \multirow[t]{2}{*}{ Test } & \multirow[t]{2}{*}{ Species } & \multirow[t]{2}{*}{ Strain } & \multicolumn{2}{|c|}{ F. exasperata } & \multicolumn{2}{|c|}{ A. muricata } & \multicolumn{2}{|c|}{ A. indica } \\
\hline & & & Aqueous & CSL & Aqueous & CSL & Aqueous & CSL \\
\hline \multirow[t]{5}{*}{ MIC } & C. albicans & - & - & 12.5 & 12.5 & 12.5 & - & - \\
\hline & C. krusei & Strain A & 12.5 & 6.25 & 6.25 & 6.25 & - & - \\
\hline & & Strain B & 12.5 & 6.25 & 6.25 & 6.25 & - & - \\
\hline & C. kefyr & Strain A & 12.5 & 6.25 & 6.25 & 3.125 & 25 & 12.5 \\
\hline & & Strain B & 6.25 & 6.25 & 6.25 & 3.125 & 25 & 12.5 \\
\hline \multirow[t]{5}{*}{ MFC } & C. albicans & - & - & 25 & 25 & 25 & - & - \\
\hline & C. krusei & Strain A & 25 & 12.5 & 12.5 & 12.5 & - & - \\
\hline & & Strain B & 25 & 12.5 & 12.5 & 12.5 & - & - \\
\hline & C. kefyr & Strain A & 25 & 12.5 & 12.5 & 6.25 & - & 25 \\
\hline & & Strain B & 12.5 & 12.5 & 12.5 & 6.25 & - & 25 \\
\hline
\end{tabular}


F. exasperata ranged between $6.25-12.5 \mathrm{mg} / \mathrm{mL}$, though the aqueous extract was found to have no activity against cultures of $C$. albicans, The MIC for CSL and aqueous extracts of $A$. muricata ranged from $3.125-12.5 \mathrm{mg} / \mathrm{mL}$, while the aqueous and CSL extracts of $A$. indica were found to have no activity at all the tested concentrations against $C$. albicans, $C$. krusei (Strain A) and C. krusei (Strain B). The MFC of both aqueous and CSL extracts was determined as the lowest concentration of the plant extracts that did not permit any visible growth of the inoculated test organism in broth culture. The aqueous extract of $F$. exasperata recorded no inhibition against $C$. albicans at the tested concentration range while the MFC of the aqueous and CSL extract against the other strains ranged from 12.5-25 $\mathrm{mg} / \mathrm{mL}$. The aqueous extract of $A$. indica gave no inhibition at the tested concentration range.

\section{DISCUSSION}

Many communities in the developing world continue to rely on the use of herbs for primary health care purposes. In the traditional medicinal applications, water and CSL are two of the commonly used solvent to prepare herbal decoction used to treat various ailments including fungal infection. Data available from the literature indicates that little or no information is available on the antifungal activity of the CSL extracts of the studied plants. Thus, in this study, the antifungal activity of the aqueous and CSL extracts of F. exasperata, A. muricata, $A$. indica were tested against Candida species isolated from high vaginal swab (HVS) samples. The presence of Candida in the HVS was ascertained, the genus Candida often forms the normal flora of the vagina, where some species may become opportunistic pathogens, if the defence mechanism of the host is weak (Bader et al., 2003). These Candida species in the vaginal flora are known to be responsible for candidiasis under low immunity. Three species of Candida (C. albicans, C. kefyr and C. krusei) were isolated from high vaginal swab samples, this agrees with previously reported studies in many countries that demonstrated that some of the prevalent yeast isolated from HVS were C. albicans, C. krusei and C. kefyr (Asticcioli et al., 2009; Ellabib and ElJariny, 2001; Hamza et al., 2008; Mohanty et al., 2007). Candidiasis has often been treated in hospitals with antibiotics. However, some reports have been published on the increasing development of resistance of microorganisms to antibiotics (Levy, 2002). Furthermore, studies have also shown that antibiotics usage for different human ailments including prophylactic and preventive purposes as well as the general well-being of the body have contributed to the increasing rise in resistance to antibiotics (Kothavade et al., 2010). Thus, it is not surprising that Candida species isolated from this study showed varying reactions to the commercially available antibiotics. C. albicans was found to be susceptible to Amphotericin B with the zone of inhibition of $21 \mathrm{~mm}$ while it was resistant to Fluconazole and Ketonidazole. The results of this study are consistent with a previous study which also suggest susceptibility pattern of Candida species to a diverse range of antibiotic (Hamza et al., 2008). The result from the antifungal testing of the aqueous and CSL extract of the studied plants suggests that both $F$. exasperata and $A$. muricata had a possible antifungal effect against the isolated Candida strains at higher concentration showing a partial dosedependent trend, the CSL extract was found to particularly elicit greater antifungal effect that the aqueous extracts. It seems possible that this may be due to the presence of lactic acid bacteria and other bioactive components in the CSL which may have contributed to the increased extractive ability of the bioactive substances present in the medicinal plants. Furthermore, it is noteworthy that CSL on its own has been demonstrated to possess antibacterial activity (Abdus-Salaam et al., 2014); other solvent extracts of F. exasperata root bark have also been reported to possess significant activity against Candida species (Lawal et al., 2012), this corresponds with the findings in this study for both the aqueous and CSL leave extracts of F. exasperata. At lower concentration, the aqueous extract of $A$. indica was found to have little or no activity against C. albicans, C. kefyr (Strain B), and C. krusei (Strain B), while a dose-dependent inhibition was observed against $C$. albicans by the CSL extract of $A$. muricata. This trend is in agreement with the observations reported by Olaiya et al. (2016) where CSL extracts of Citrullus colocynthis, Curculigo pilosa and Gladiolus psittacinus demonstrated significant antibacterial effect against Staphylococcus aureus, Escherichia coli, Klebsiella pneumonae and Salmonella typhi. However, F. exasperata extract was reported to have no activity against $C$. albicans in the study by Adebayo et al. (2009) which is contrary to the findings in this study; this may be a reflection of the effect of the different solvent type used in the study. Various solvent extracts of $A$. muricata have been shown to exhibit antibacterial activity (Vijayameena et al., 2013). The findings in this study also matched those observed in the study by Pai et al. (2010) where an aqueous extract of A. muricata was reported to be highly effective against Candida species; it is also noteworthy that both aqueous and CSL extracts of $A$. muricata showed better activity against $C$. kefyr (Strain A) than all the conventional antibiotics. The minimal antifungal activity of $A$. indica extracts observed in this study mirrors those reported by Mahmoud et al. (2011) where little activity was found against $C$. albicans, though, in another study, tissue conditional mixed with $A$. indica extracts at two concentrations was reported to exhibit considerable potential effectiveness against C. albicans (Barua et al., 2017). The MIC values revealed that the aqueous and CSL leave extracts of the F. exasperata inhibited the growth of four of the tested pathogens within range of $6.25-12.5 \mathrm{mg} / \mathrm{mL}$. The MIC for the aqueous and CSL extract of $A$. muricata ranged between 6.25$12.5 \mathrm{mg} / \mathrm{mL}$ and $3.125-12.5 \mathrm{mg} / \mathrm{mL}$ respectively, this shows the potential of the plant extract to inhibit the growth of the human fungal pathogens, however, only two of the Candida species gave a MIC value for $A$. indica extracts with the CSL extract inhibiting both strains of $C$. kefyr at a concentration of $12.25 \mathrm{mg} / \mathrm{mL}$ and no inhibition observed at the tested concentration ranged against the other Candida strains. In the same manner, the fungicidal effect of the tested extracts shows that only the aqueous extract of $F$. exasperata did not demonstrate a fungicidal effect against $C$. albicans at the tested concentration range. The MFC of the plant extracts tends towards the mid concentration for most of the plant extracts that showed activity with CSL extract of $A$. indica only demonstrating fungicidal action at $25 \mathrm{mg} / \mathrm{mL}$ against the two strains of $C$. kefyr. This observation justifies the use of this plant as an antimicrobial agent in traditional medicine. The antifungal activity shown by the extracts of the studied plants may be attributed to the presence of the secondary metabolites that were detected to be present in both the aqueous and CSL extracts of the F. exasperata, A. muricata and A. indica, this observation also supports the findings in other similar studies on different extracts of the studied plants (Iyanda-Joel et al., 2019; Nimenibo-uadia, 2017; Saleh Al-Hashemi and Hossain, 2016; Vijayameena et al., 2013). Some researchers have demonstrated the antifungal effects of various forms of tannin tested against a wide range of fungi including Candida species (Morey et al., 2016; Latté and Kolodziej, 2000), similarly, saponin rich extracts isolated from plants have also been reported to have good activity against Candida species (Coleman et al., 2010; Tsuzuki et al., 2007; Yang et al., 2006; 2018); likewise, the bioactivity of flavonoids and polyphenolics against Candida species have been documented (Patuwo et al., 2014; Salazar-Aranda et al., 2015). These evidence suggest that the antifungal activity elicited by the CSL and aqueous extracts of the plants may be due to the pres- 
ence of these phytochemicals whether working alone or in synergy which could therefore, justify their folkloric use in alternative medicine. However, further studies are needed to isolate specific phytochemical compounds present in the CSL and aqueous extracts of the plants which may be responsible for the antifungal activity.

\section{CONCLUSION}

This study has shown the antifungal efficacy of aqueous and CSL extracts of $F$. exasperata, $A$. muricata, and $A$. indica against isolates of Candida species which are usually implicated in candidiasis, thereby providing additional evidence on the antimicrobial activity of CSL extracts of the plants; this has been attributed to its phytochemical extractive ability which is known to elicit antifungal activities.

\section{ACKNOWLEDGMENTS}

The authors are grateful to the microbiology section of the Federal Medical Centre, Abeokuta for providing the high vaginal swab samples and also to Mrs. Rafiu B. O of BMRC, FRIN for technical assistance during the laboratory analysis and the Forest Herbarium Ibadan for identifying the plant samples.

\section{REFERENCES}

Abdus-Salaam, R. B., Adepoju, P. A., Olaleye, O. N. and Adeoye, I. A. (2014). Studies on the antimicrobial effect of corn steep liquor on some diarrhoea causing organisms, African Journal of Biotechnology 13(2): 332-335.

Adebayo, E., Ishola, O., Taiwo, O., Majolagbe, O. and Adekeye, B. (2009). Evaluations of the methanol extract of Ficus exasperata stem bark, leaf and root for phytochemical analysis and antimicrobial activities, African Journal of Plant Science 3(12): 283-287.

Ajayi, O. B., Oluyege, J. O., Olalemi, O. M. and Ilesanmi, T. M. (2012). Nutritional composition, phytochemical screening and antimicrobial properties of the leaf of Ficus exasperata (Vahl), Asian Journal of Biological and Life Sciences 1(3): 242246.

Asticcioli, S., L., S., Daturi, R., Matti, C., Nucleo, E., Zara, F. and Pagani, L. (2009). Trends in frequency and in vitro antifungal susceptibility patterns of Candida isolates from women attending the STD outpatients clinic of a tertiary care hospital in Northern Italy during the years 2002-2007. The new Microbiologica 32(2): 199-204.

Bader, T., Bodendorfer, B., Schröppel, K. and Morschhäuser, J. (2003). Calcineurin is essential for virulence in Candida albicans, Infection and Immunity 71(9): 5344-5354.

Bafor, E. and Igbinuwen, O. (2009). Acute toxicity studies of the leaf extract of Ficus exasperata on haematological parameters, body weight and body temperature, Journal of Ethnopharmacology 123(2): 302-307.

Barua, D., Basavanna, J. and Varghese, R. (2017). Efficacy of neem extract and three antimicrobial agents incorporated into tissue conditioner in inhibiting the growth of C. albicans and S. mutans, Journal of clinical and diagnostic research 11(5): ZC97-ZC101.

Calderone, R. A. and Fonzi, W. A. (2001). Virulence factors of Candida albicans, Trends in Microbiology 9(7): 327-335.
Choudhary, S., Dwivedi, A. K. and Singh, P. (2017). Antifungal activities of neem leaf extracts on the growth of Macrophomina phaseolina in vitro and its chemical characterization, IOSR Journal of Environmental Science, Toxicology and Food Technology 11(4): 44-48.

Coleman, J. J., Okoli, I., Tegos, G. P., Holson, E. B., Wagner, F. F., Hamblin, M. R. and Mylonakis, E. (2010). Characterization of plant-derived saponin natural products against Candida albicans, ACS Chemical Biology 5(3): 321-332.

Ellabib, M. S. and ElJariny, I. A. (2001). In vitro activity of 6 antifungal agents on Candida species isolated as causative agents from vaginal and other clinical specimens, Saudi Journal of Medicine 22(10): 860-863.

Galle, L. C. and Gianinni, M. J. S. M. (2004). Prevalência e susceptibilidade de leveduras vaginais, Jornal Brasileiro de Patologia e Medicina Laboratorial 40(4): 229-236.

Hamza, O. J., Matee, M. I., Moshi, M. J., Simon, E. N., Mugusi, F., Mikx, F. H., Helderman, W., Rijs, A. J., van der Ven, A. J. and Verweij, P. E. (2008). Species distribution and in vitro antifungal susceptibility of oral yeast isolates from Tanzanian HIV-infected patients with primary and recurrent oropharyngeal candidiasis, BMC Microbiology 8(1): 135.

Harborne, J. B. (1973). Phytochemical Methods: A Guide to Modern Techniques of Plant Analysis, Springer Netherlands.

Hutchinson, J. and Dalziel, J. (2000). Flora of West Tropical Africa Volume 1 Part 2, Royal Botanic Gardens, Kew.

Itelima, J., Nwokedi, V., Ogbonna, A. and Nyam, M. (2016). Phytochemical screening and antimicrobial activity evaluation of aqueous and ethanolic extracts of the leaf of Azadirachta indica Juss (neem) on some microorganisms, World Journal of Microbiology 3(1): 56-60.

Iyanda-Joel, W. O., Omonigbehin, E. A., Iweala, E. E. J. and Chinedu, S. N. (2019). Antibacterial studies on fruit-skin and leaf extracts of Annona muricata in Ota, Nigeria, IOP Conference Series: Earth and Environmental Science 331: 012029.

Kanthasamy, A., Subramanian, S. and Govindasamy, S. (1989). Bactericidal and fungicidal effects of Prosopis juliflora alkaloidal fraction, Indian Drugs 26: 390-394.

Kareem, K., Kareem, S., Adeyemo, O. and Egberongbe, R. (2010). In vitro antimicrobial properties of Bridelia ferruginea on some clinical isolates, Agriculture and Biology Journal of North America 1(3): 416-420.

Kothavade, R. J., Kura, M. M., Valand, A. G. and Panthaki, M. H. (2010). Candida tropicalis: its prevalence, pathogenicity and increasing resistance to fluconazole, Journal of Medical Microbiology 59(8): 873-880.

Latté, K. P. and Kolodziej, H. (2000). Antifungal effects of hydrolysable tannins and related compounds on dermatophytes, mould fungi and yeasts, Zeitschrift für Naturforschung C 55(5-6): 467-472.

Lawal, I., Borokini, T., Oyeleye, A., Williams, O. and Olayemi, J. (2012). Evaluation of extract of Ficus exasperata Vahl. root bark for antimicrobial activities against some strains of clinical isolates of bacterial and fungi, International Journal of Modern Botany 2(1): 6-12.

Levinson, W. E. (2016). Review of Medical Microbiology and Immunology 14E, McGraw-Hill Education. Google-BooksID: TPnnCwAAQBAJ. 
Levy, S. B. (2002). Factors impacting on the problem of antibiotic resistance, Journal of Antimicrobial Chemotherapy 49(1): 25-30.

Mahmoud, D., Hassanein, N., Youssef, K. and Abou Zeid, M. (2011). Antifungal activity of different neem leaf extracts and the nimonol against some important human pathogens, Brazilian Journal of Microbiology 42(3): 1007-1016.

Malwal, M. and Sarin, R. (2011). Antimicrobial efficacy of Murraya koenigii (Linn.) Spreng. root extracts, Indian Journal of Natural Products and Resources 2(1): 48-51.

McLaughlin, J. L. (2008). Paw paw and cancer: Annonaceous acetogenins from discovery to commercial products, Journal of Natural Products 71(7): 1311-1321.

Mohammed, H. A. and Omer, A. F. A. (2017). Antibacterial activity of Azadirachta indica (neem) leaf extract against bacterial pathogens in Sudan, Ameri-can Journal of Research and Communication 3(5): 246-251.

Mohanty, S., Xess, I., Hasan, F., Kapil, A., Mittal, S. and Tolosa, J. E. (2007). Prevalence \& susceptibility to fluconazole of Candida species causing vulvovaginitis, The Indian Journal of Medical Research 126(3): 216-219.

Mondall, N., Mojumdar, A., Chatterje, S., Banerjee, A., Datta, J. and Gupta, S. (2009). Antifungal activities and chemical characterization of neem leaf extracts on the growth of some selected fungal species in vitro culture medium, Journal of Applied Science and Environmental Management 13(1): 49-53.

Morey, A. T., de Souza, F. C., Santos, J. P., Pereira, C. A., Cardoso, J. D., de Almeida, R. S., Costa, M. A., de Mello, J. C., Nakamura, C. V., Pinge-Filho, P., Yamauchi, L. M. and Yamada-Ogatta, S. F. (2016). Antifungal activity of condensed tannins from Stryphnodendron adstringens: effect on Candida tropicalis growth and adhesion properties, Current Pharmaceutical Biotechnology 17(4): 365-375.

Nahak, G. and Sahu, R. K. (2010). In vitro antioxidative acitivity of Azadirachta indica and Melia azedarach leaves by DPPH scavenging assay, Journal of American Science 6(6): 123-128.

Nimenibo-uadia, R. (2017). Chemical composition and phytochemical screening of Ficus exasperata (Vahl) leaf, Nigerian Journal of Pharmaceutical and Applied Science Research 6(1): 1218.

Obasi, N., Egbuonu, A., Ukoha, P. and Ejikeme, P. (2010). Comparative phytochemical and antimicrobial screening of some solvent extracts of Samanea saman pods, African Journal of Pure and Applied Chemistry 4(9): 206-212.

Oberlies, N. H., Jones, J. L., Corbett, T. H., Fotopoulos, S. S. and McLaughlin, J. L. (1995). Tumor cell growth inhibition by several Annonaceous acetogenins in an in vitro disk diffusion assay, Cancer Letters 96(1): 55-62.

Olaiya, C., Idowu, P. and Karigidi, K. (2016). Antioxidative and antimicrobial activities of corn steep liquor anti-diabetic herb extracts, Annals. Food Science and Technology 17(2): 272279.

Pai, M. B. H., Prashant, G. M., Murlikrishna, K. S., Shivakumar, K. M. and Chandu, G. N. (2010). Antifungal efficacy of Punica granatum, Acacia nilotica, Cuminum cyminum and Foeniculum vulgare on Candida albicans: an in vitro study, Indian Journal of Dental Research: Official Publication of Indian Society for Dental Research 21(3): 334-336.
Patuwo, C., Pasetto, S., Youngr, K. and Murata, M. (2014). Antifungal activity of flavonoids against Candida albicans, 43rd Annual Meeting E Exhibition of the AADR.

Pfaller, M. A. and Diekema, D. J. (2007). Epidemiology of invasive candidiasis: a persistent public health problem, Clinical Microbiology Reviews 20(1): 133-163.

Pierce, G. E. (2005). Pseudomonas aeruginosa, Candida albicans, and device-related nosocomial infections: implications, trends, and potential approaches for control, Journal of Industrial Microbiology \& Biotechnology 32(7): 309-318.

Pinto, E., Vale-Silva, L., Cavaleiro, C. and Salgueiro, L. (2009). Antifungal activity of the clove essential oil from Syzygium aromaticum on Candida, Aspergillus and dermatophyte species, Journal of Medical Microbiology 58(11): 1454-1462.

Prusti, A., Mishea, S., Sahoo, S. and Mishea, S. (2008). Antibacterial activity of some indian medicinal plants, Ethanobotanical leaflets 12: 227-228.

Rahman, A., Samoylenko, V., Jacob, M., Sahu, R., Jain, S., Khan, S., Tekwani, B. and Muhammad, I. (2011). Antiparasitic and antimicrobial indolizidines from the leaves of Prosopis glandulosa var. glandulosa, Planta Medica 77(14): 1639-1643.

Roopashree, T. S., Dang, R., Rani, R. S. and Narendra, C. (2008). Antibacterial activity of antipsoriatic herbs: Cassia tora, Momordica charantia and Calendula officinalis, International Journal of Applied Research in Natural Products 1(2): 20-28.

Salazar-Aranda, R., Granados-Guzmán, G., Pérez-Meseguer, J., González, G. and de Torres, N. (2015). Activity of polyphenolic compounds against Candida glabrata, Molecules 20(10): 17903-17912.

Saleh Al-Hashemi, Z. S. and Hossain, M. A. (2016). Biological activities of different neem leaf crude extracts used locally in Ayurvedic medicine, Pacific Science Review A: Natural Science and Engineering 18(2): 128-131.

Shah, S., Nasreen, S. and Sheikh, P. (2012). Cultural and morphological characterization of Trichoderma spp. associated with green mold disease of Pleurotus spp. in Kashmir, Research Journal of Microbiology 7(2): 139-144.

Sonibare, M. A., Ogunwande, I. A., Walker, T. M., Setzer, W. N., Soladoye, M. O. and Essien, E. (2006). Volatile constituents of Ficus exasperata leaves, Natural Product Communications 1(9): 1934578X0600100.

Takon, I. (2013). In-vitro evaluation of antibacterial activity of ethanolic and aqueous extracts of Ficus exasperata vahl. (Moraceae) leaves, Journal of Microbiology and Biotechnology Research 3(4): 7-12.

Tsai, P.-W., Chen, Y.-T., Hsu, P.-C. and Lan, C.-Y. (2013). Study of Candida albicans and its interactions with the host: A mini review, BioMedicine 3(1): 51-64.

Tsuzuki, J. K., Svidzinski, T. I., Shinobu, C. S., Silva, L. F., Rodrigues-Filho, E., Cortez, D. A. and Ferreira, I. C. (2007). Antifungal activity of the extracts and saponins from Sapindus saponaria L., Anais da Academia Brasileira de Ciências 79(4): 577-583.

Vijayameena, C., Subhashini, G., Loganayagi, M. and Ramesh, B. (2013). Phytochemical screening and assessment of antibacterial activity for the bioactive compounds in Annona muricata, International Journal of Current Microbiology and Applied Sciences 2(1): 1-8. 
Yang, C.-R., Zhang, Y., Jacob, M. R., Khan, S. I., Zhang, Y.-J. and Li, X.-C. (2006). Antifungal activity of C-27 steroidal saponins, Antimicrobial Agents and Chemotherapy 50(5): 17101714.

Yang, L., Liu, X., Zhuang, X., Feng, X., Zhong, L. and Ma, T. (2018). Antifungal effects of saponin extract from rhizomes of Dioscorea panthaica Prain et Burk against Candida albicans, Evidence-Based Complementary and Alternative Medicine 2018: Article ID 6095307. 